\title{
"Malignant" mitral stenosis
}

\author{
Johann Auer ${ }^{1,2^{*}}$, Robert Berent ${ }^{3}$ and Franz Gurtner ${ }^{1}$
}

\begin{abstract}
Symptomatic mitral stenosis caused by a left atrial mass as the first sign of metastasis of a malignant tumor is extremely rare and frequently associated with poor prognosis. We report a case of a 59-year-old man with a history of grade 3 malignant fibrous histiocytoma on his left tigh treated by limb-sparing surgery 17 months earlier, who was admitted with 10-days of worsening dyspnea. Imaging revealed a left atrial mass protruding through the mitral valve that resulted in severe mitral stenosis. Biopsy confirmed metastasis of malignant fibrous histiocytoma.
\end{abstract}

Keywords: Metastasis, Heart failure, Dyspnea, Echocardiography, Computed tomography

\section{Background}

Symptomatic mitral stenosis caused by a left atrial mass as the first sign of metastasis of a malignant tumor is extremely rare and frequently associated with poor prognosis. Atrial tumours presenting as mitral stenosis are most commonly myxomata, occasionally pedunculated sarcoma, and very rarely metastases.

\section{Case Presentation}

A 59-year-old man with a history of grade 3 malignant fibrous histiocytoma on his left tigh Stage IIA (pT1bN0M0) treated by limb-sparing surgery 17 months earlier, was admitted with 10-days of worsening dyspnea. The patient underwent postoperative chemotherapy after surgery and had follow up visits every six months. Blood pressure and heart rate were 150/85 $\mathrm{mmHg}$ and 136 beats/minute, respectively. Cardiac auscultation revealed a diastolic murmur. End-inspiratory crackles suggested pulmonary edema. Echocardiography revealed a left atrial mass protruding through the mitral valve (Figures 1 and 2). Continous wave spectral Doppler showed mitral stenosis with a mitral valve area less than $1.0 \mathrm{~cm}^{2}$ (Figures 3 and 4). Additionally, a giant mass in the left pleural space penetrating the left pulmonary veins could be demonstrated by ultrasound (Figures 5 and 6) and by computed tomography (Figures 7 and 8). Biopsy of the pleural tumor revealed metastasis of malignant fibrous histiocytoma (Figure 9). Pulmonary edema resolved with symptomatic treatment. Before

\footnotetext{
* Correspondence: johann.auer@khbr.at

'Department of Cardiology and Intensive Care, General Hospital Braunau, Braunau, Austria

Full list of author information is available at the end of the article
}

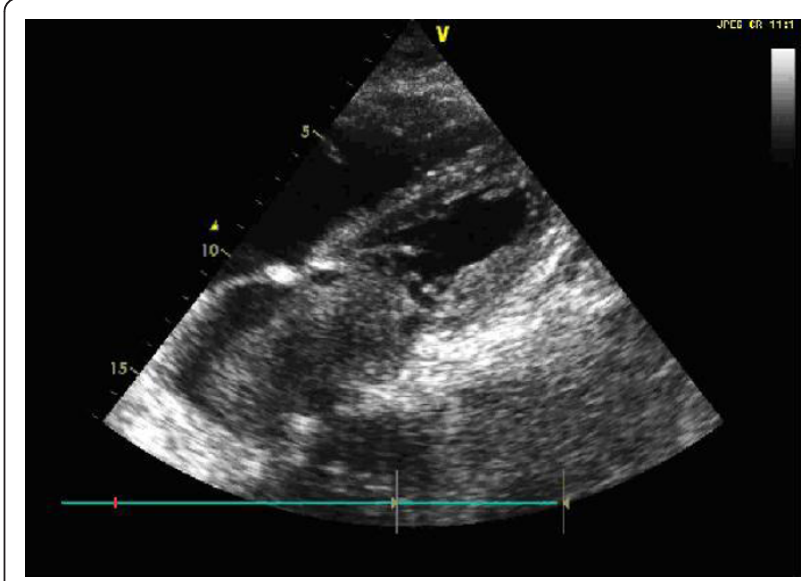

Figure 1 Echocardiography shows a giant left atrial mass.

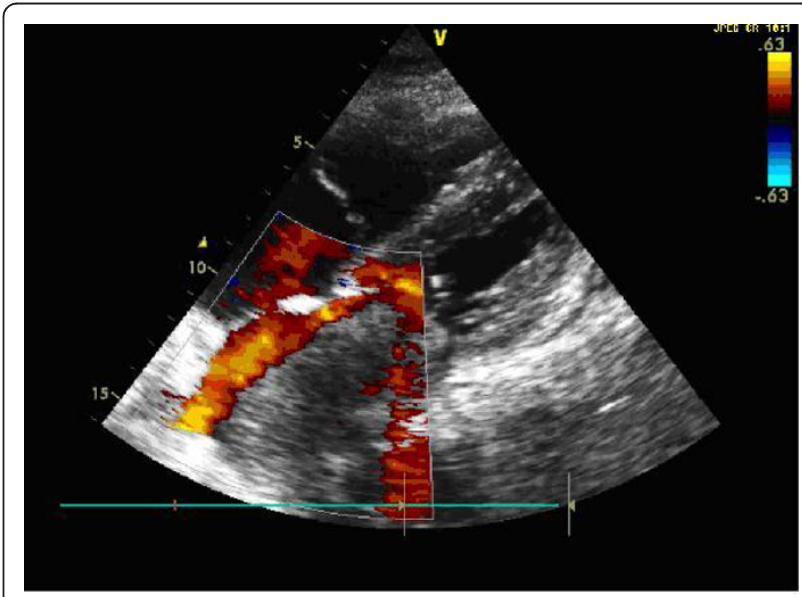

Figure 2 Echocardiogram with a left atrial mass protruding through the mitral valve. 


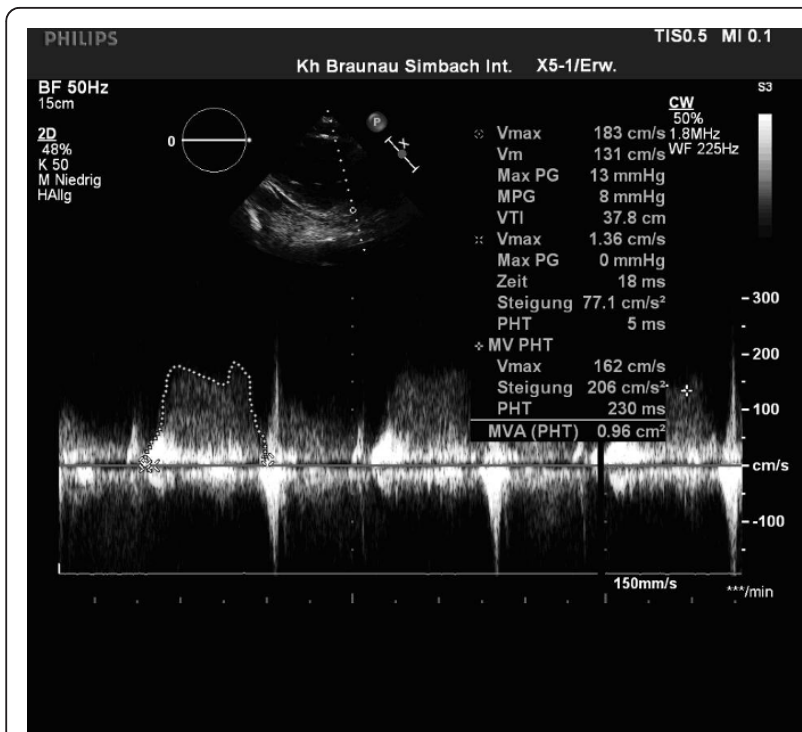

Figure 3 Continous wave (CW) - spectral Doppler tracing indicating mitral stenosis with a mitral valve area less than $\mathbf{1 . 0}$ $\mathrm{cm} 2$.

discussing further treatment options, the patient died suddenly four days after admission.

\section{Conclusion}

Atrial tumours presenting as mitral stenosis are most commonly myxomata, occasionally pedunculated sarcoma, and very rarely metastases $[1,2]$.

Symptomatic mitral stenosis caused by a left atrial mass as the first sign of metastasis of a malignant tumor is extremely rare and frequently associated with poor

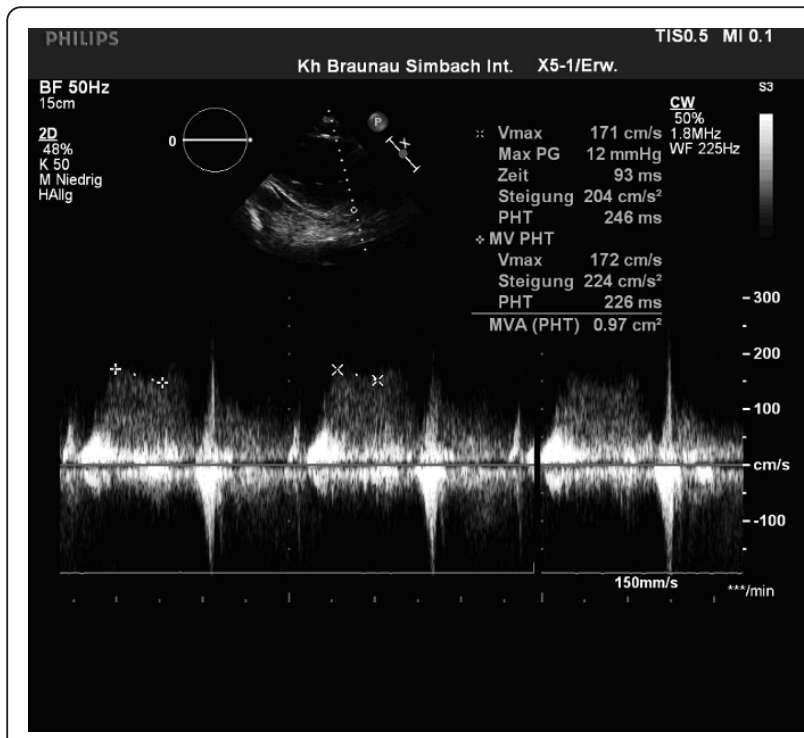

Figure $4 \mathrm{CW}$ - spectral Doppler tracing indicating severe mitral stenosis.

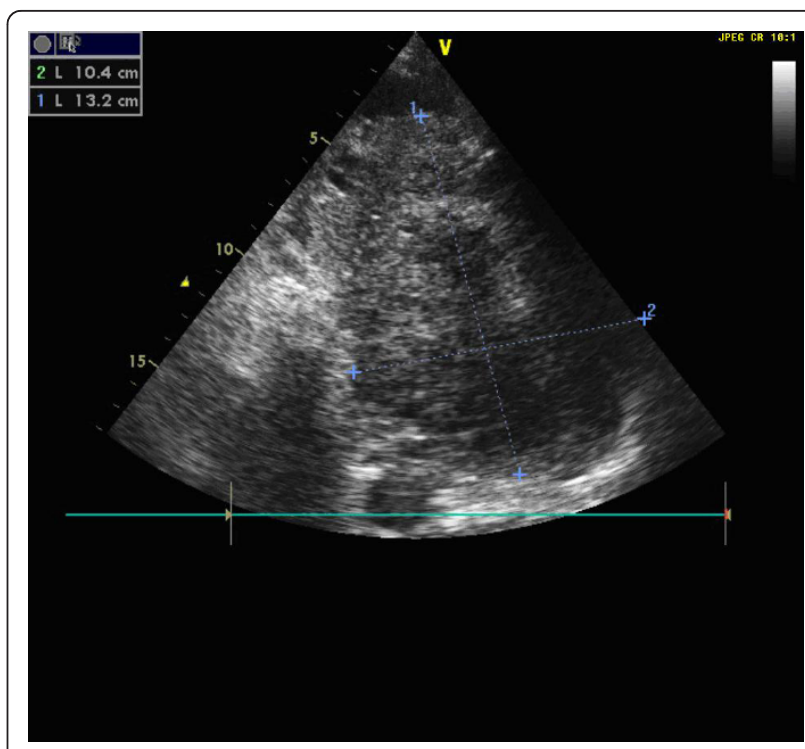

Figure 5 Sonography demonstrating a giant mass in the left pleural space penetrating the left pulmonary veins

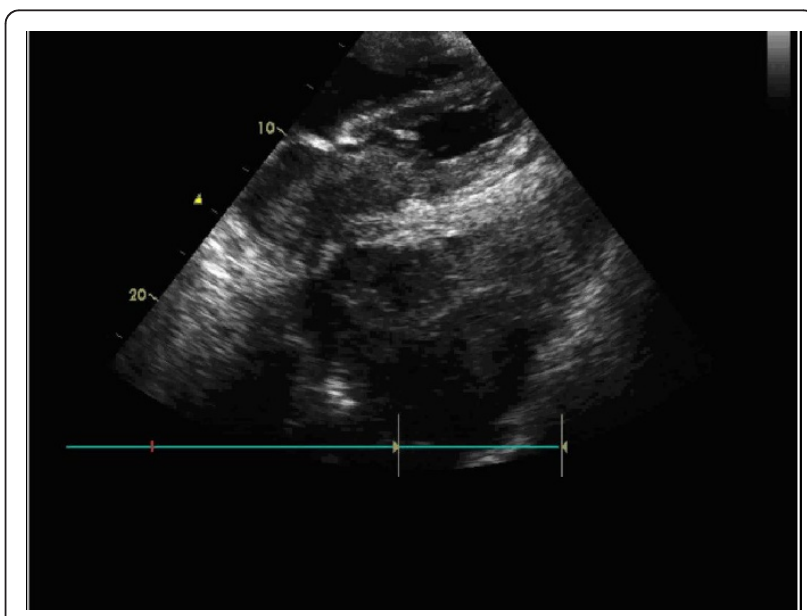

Figure 6 Sonography with a large mass in the left pleural space.

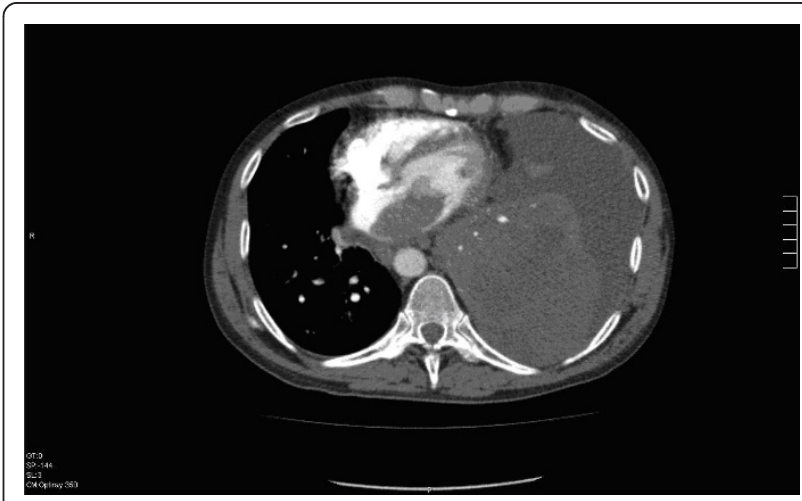

Figure 7 Computed tomography shows a large mass in the left pleural space. 


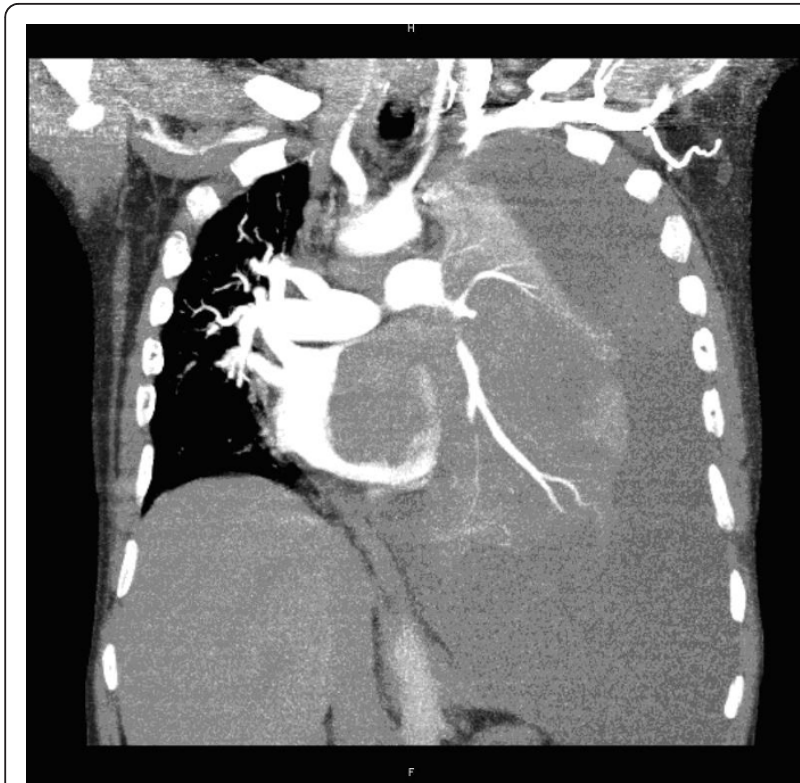

Figure $\mathbf{8}$ Computed tomography shows a large mass in the left pleural space penetrating the left pulmonary veins and protruding to the left atrium and through the mitral valve.

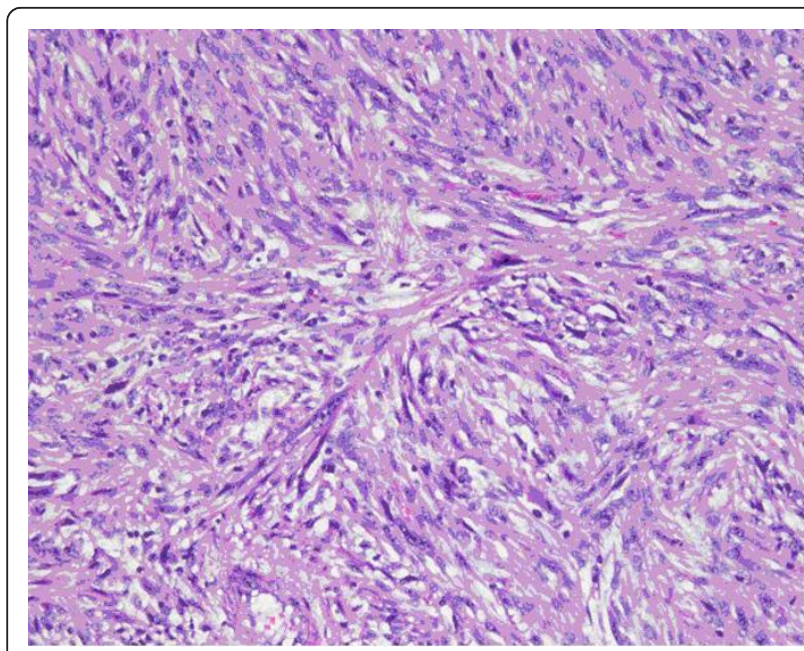

Figure 9 Biopsy of the pleural tumor revealed metastasis of malignant fibrous histiocytoma

prognosis [1-3]. However, there are some reports about successful favourable response with combined treatment particularly in patients with high tumor mitotic rate $[4,5]$.

\section{Consent}

Written informed consent was obtained from the patient for publication of this report and any accompanying images.

\section{Acknowledgements}

We would like to acknowledge and thank Dr. Günter Schatzl and Dr. Carina Primus for their support and critical reviews.

\section{Author details}

'Department of Cardiology and Intensive Care, General Hospital Braunau, Braunau, Austria. ${ }^{2}$ Department of Cardiology and Intensive Care, General Hospital Simbach, Simbach, Germany. ${ }^{3}$ Center of Cardiac Rehabilitation, Bad Schallerbach, Austria.

\section{Authors' contributions}

JA wrote the manuscript and formatted the images. FG provided cardiovascular images and reports. RB supervised and revised the draft manuscript. All authors read and approved the final manuscript.

\section{Competing interests}

The authors declare that they have no competing interests.

Received: 3 November 2011 Accepted: 8 March 2012

Published: 8 March 2012

\section{References}

1. Reynen K, Köckeritz U, Strasser RH: Metastases to the heart. Ann Oncol 2004, 15:375-381.

2. Stems LP, Eliot RS, Varco RL, Edwards JE: Intracavitary cardiac neoplasms. A review of fifteen cases. Br Heart J 1966, 28:7543-7546.

3. Hepp A, Larbig D, Bader H: Left atrial metastasis of chorion carcinoma, presenting as mitral stenosis. Br Heart J 1977, 39:1154-1156.

4. Recchia F, Saggio G, Amiconi G, Di Blasio A, Cesta A, Candeloro G, Rea S, Nappi G: Cardiac metastases in malignant fibrous histiocytoma. A case report. Tumori 2006, 92:76-78.

5. Schena S, Caniglia A, Agnino A, Caruso G, Ferlan G: Survival following treatment of a cardiac malignant fibrous histiocytoma. Chest 2000, 118:271-273.

doi:10.1186/1749-8090-7-19

Cite this article as: Auer et al.: "Malignant" mitral stenosis. Journal of Cardiothoracic Surgery 2012 7:19.

\section{Submit your next manuscript to BioMed Central and take full advantage of:}

- Convenient online submission

- Thorough peer review

- No space constraints or color figure charges

- Immediate publication on acceptance

- Inclusion in PubMed, CAS, Scopus and Google Scholar

- Research which is freely available for redistribution 